\title{
Proceedings from the IV Brazilian Meeting on Research Integrity, Science and Publication Ethics (IV BRISPE)
}

\author{
Goiânia, Brasil. 17-18 November 2016
}

Published: 14 June 2017

\section{Proceedings of the IV Brazilian Meeting on Research Integrity (IV BRISPE)}

\author{
Sonia Vasconcelos ${ }^{1,2}$, Edson Watanabe $e^{2,3}$ \\ ${ }^{1}$ Science Education Program, Institute of Medical Biochemistry Leopoldo \\ de Meis (IBqM), Federal University of Rio de Janeiro (UFRJ), Rio de \\ Janeiro, Brazil; ${ }^{2}$ Committee on Research Integrity (CRI), Advisory Council \\ for Research Ethics (CTEP), Federal University of Rio de Janeiro (UFRJ), \\ Rio de Janeiro, Brazil; ${ }^{3}$ Electrical Engineering Program (PEE), Institute \\ Alberto Luiz Coimbra of Graduate Studies and Research in Engineering \\ (COPPE), Federal University of Rio de Janeiro (UFRJ), Rio de Janeiro, Brazil \\ Research Integrity and Peer Review 2017, 2(Suppl 1):
}

The Brazilian Meeting on Research Integrity, Science and Publication Ethics (BRISPE) has been held every two years since 2010 in Brazil. The BRISPE has been the major forum for discussion of research integrity in the country. Although it is a national meeting, it has strengthened the role Brazilian science has played in international conversations on the responsible conduct of research. In 2010, the I BRISPE (www.ibrispe.coppe.ufrj.br) focused on research integrity issues related to research projects, to the submission and review process of manuscripts, and to authorship. In 2012, the II BRISPE (www.iibrispe.coppe.ufrj.br) addressed research integrity and leadership in science. The meeting looked at the country's responsibility to foster responsible research, considering its scientific leadership in Latin America. The meeting led to the publication of the Joint Statement on Research Integrity, (www.iibrispe.coppe.ufri.br/ images/IBRRISPE/JoinStatement/JointStatementonResearchlntegrity_IIBRISPE_2012_English.pdf). In 2014, the III BRISPE (http://www.fapesp.br/8788) focused on institutional policies to foster research integrity initiatives at universities and research centers in Brazil. Locally, the III BRISPE was also a preparatory meeting for the $4^{\text {th }}$ World Conference on Research Integrity, which was held in Rio de Janeiro, in 2015 (www.wcri2015.org). In 2016, the IV BRISPE (www.brispe2016.org) drew upon the role of mentors, editors and funders to strengthen a research integrity culture in Brazilian science. The event was held at the Federal University of Goiás (UFG), November 17-18, 2016, with 260 participants. For this fourth edition of the meeting, there was a call for submissions for oral and poster sessions on research and education and on science policy. From 40 submissions, 34 were accepted.

The Proceedings of the IV BRISPE contain the abstracts of oral and poster presentations of authors who agreed to have them published. The V BRISPE will be held in 2018.

\author{
Acknowledgments \\ We would like to thank the local co-chairs at UFG, Dr. Sheila Teles and \\ Dr. Clorinda Fioravanti, who had a crucial role in the organization of the IV \\ BRISPE. We also thank Dr. Martha Sorenson for her assistance in the \\ production of these Proceedings.
}

\section{Poster presentations}

PT.01

Ethical considerations in original articles published in Epidemiology and Health Services: Journal of the Brazilian National Health System, 2014-2016

L. P. Garcia ${ }^{1}$, E. Duarte

${ }^{1}$ Institute for Applied Economic Research (IPEA), Brasília, Federal District, Brazil; ${ }^{2}$ Secretary for Health Surveillance, Ministry of Health, Brasília,

Federal District, Brazil

Correspondence: L. P. Garcia (leilapgarcia@gmail.com)

Research Integrity and Peer Review 2017, 2(Suppl 1):PT.01

Epidemiology and Health Services: Journal of the Brazilian National Health System is a scientific quarterly journal published by the Brazilian Ministry of Health. The journal publishes mainly original articles that report research involving human subjects, in accordance with its mission: to disseminate epidemiological knowledge applicable to surveillance, prevention and disease control relevant to Public Health. This report aims to describe the ethical considerations presented in the original articles published from 2014 (v. 23, n. 1) to 2016 (v. 25, n. 1). One hundred forty-seven original articles were published (10 issues), 8 were excluded because they did not report research involving human subjects. We checked for the description of the following items in the Methods section: Human Research Ethics Committee (HREC) approval, date of approval, registry number, and informed consent. We reviewed 139 original articles. HREC approval was mentioned in 45/45 articles that reported use of primary data, $16 / 16$ that reported use of secondary data from surveys, 30/62 that reported use of secondary data from health information systems, 12/13 that reported use of medical records, and $3 / 3$ that reported studies conducted with both primary and secondary data. All 48 articles that reported studies with primary data described the HREC registry number, 34 mentioned obtaining of informed consent, and 7 provided the date of HREC approval. Among the 91 articles that reported studies conducted exclusively with secondary data, 51 included HREC approval, 55 provided the registry number, and 29 the date of HREC approval. Thus, all articles that reported studies 
conducted with primary data and with secondary data from surveys included information regarding HREC approval. The reporting of HREC approval was less frequent in the articles that reported use of secondary data from health information systems, pointing to the need to standardize the ethical review procedures and ethical considerations reporting for those studies.

\section{PT.04}

Conflicts of interest: The case of phosphoethanolamine ("cancer pill")

M. C. Cassimiro ${ }^{1}$, M. M. P. Diós-Borges ${ }^{1,2}$, A. M. M. Soares ${ }^{1,3}$,

C. H. Debenedito Silva ${ }^{1,3}$, A. A. P. Santa Rosa ${ }^{3,4}$

${ }^{1}$ Scientific Integrity Committee, Oswaldo Cruz Foundation, Oswaldo Cruz Institute (IOC/FIOCRUZ), Rio de Janeiro, Brazil; ${ }^{2}$ Rio de Janeiro State University (UERJ), Rio de Janeiro, Brazil; ${ }^{3}$ National Cancer Institute (INCA), Cancer Hospital IV - Ethics Committee for Clinical Research, Rio de Janeiro, Brazil; ${ }^{4}$ Federal General Hospital of Bonsucesso, Rio de Janeiro, Brazil

Correspondence: M. C. Cassimiro (cassimir@ioc.fiocruz.br) Research Integrity and Peer Review 2017, 2(Suppl 1):PT.04

The basic principle of drug testing comes from the need to provide safe products to people, in order to improve health conditions when aggravated by illness. The episode of phosphoethanolamine presents us with an important task: to rethink how we see the rules and laws in Brazil. Balancing the need to advance in scientific research and the duty to follow the ethical research protocol was not a trivial matter given the chaotic times at national institutions and their interest in maintaining political power at all costs. The debate regarding synthetic phosphoethanolamine in Brazil is not entirely scientific. In the midst of intense academic discussion about its biochemical and clinical aspects, there is another issue in the field of Justice about the decisions that have been made for the release of phosphoethanolamine capsules to the general public. Ideally, the arguments should rely mainly on ethical criteria, necessary for a large-scale application of the results of any scientific experiment. However, the debate over phosphoethanolamine is not only about the correct application of ethical principia regulating Brazilian scientific research. These rules are currently in use, and yet, they were not enough to prevent fabrication and distribution of the substance. Government agencies should pay strong attention to this fact and become truly and responsibly committed to stimulating research on new drugs, provided that it can be carried out following ethical principia. Benefits of scientific research are supposed to consider not only the financial expenditures but also its social costs. To keep the integrity of the research on new drugs in Brazil, it is mandatory to fill the gap between scientific and social responsibilities.

\section{References}

1. Alpert JS. Doctors and the drug industry: How can we handle potential conflicts of interest?. (editorial) Am J Med. 2005; 118:99-100.

2. Angell M. The truth about the drug companies. How they deceive us and what to do about it. New York: Random House; 2004. 305 p.

3. Lei $n^{\circ} 13.269$, de 13 de abril de 2016. Autoriza o uso da fosfoetanolamina sintética por pacientes diagnosticados com neoplasia maligna. Diário Oficial da União - Seção 1 - 14/4/2016, P.1. Available at: http://www2.camara.leg.br/ legin/fed/lei/2016/lei-13269-13-abril-2016-782885-publicacaooriginal-150083pl.html.

4. Paumgartten F. On the alleged anticancer efficacy of the phosphoethanolamine pill, weakness of scientific evidence and ethical concerns. Vigil Sanit Debate 2016; 4: 4-12. Available at: http://www.scilit. net/article/10.22239/2317-269x.00822en.

5. Spece RG Jr, Shimm DS, Buchanan AE, editors. Conflicts of interest in clinical practice and research. New York: Oxford University Press; 1996. 453 p.

6. Thompson DF. Understanding financial conflicts of interest. N Eng J Med. 1993;329:573-576.

7. Viana MH. Liberação da 'Pílula do Câncer' expõe atropelo da ciência pela política. Available at:http://www.sbq.org.br/noticia/libera\%C3\%A7\%C3\% A3o-da-p\%C3\%ADlula-do-c\%C3\%A2ncer-exp\%C3\%B5e-atropelo-daci\%C3\%AAncia-pela-pol\%C3\%ADtica.

\section{PT.06}

Characterization of the research protocols evaluated by a research ethics committee: The experience in a teaching hospital

G. A. Fófano ${ }^{1,2,3}$, H. S. Pinheiro ${ }^{4}$, A. M. Gollner ${ }^{4}$

${ }^{1}$ Human Research Ethics Committee, University Hospital of Juiz de Fora (HU-UJFJ), Juiz de Fora, Minas Gerais, Brazil; ${ }^{2}$ Faculty of Southeastern Minas Gerais (FACSUM), Juiz de Fora, Minas Gerais, Brazil; ${ }^{3}$ São Pedro Educational Institute (IESPe), Juiz de Fora, Minas Gerais, Brazil; ${ }^{4}$ University Hospital of Juiz de Fora (HU-UJFJ), Juiz de Fora, Minas Gerais, Brazil

Correspondence: G. A. Fófano (giselefofano@gmail.com)

Research Integrity and Peer Review 2017, 2(Suppl 1):PT.06

The Research Ethics Committee (CEP) of the University Hospital (HU) of the Federal University of Juiz de Fora (UFJF/EBSERH) is composed of representatives of UFJF and of members of the public. It is a multidisciplinary and multiprofessional body with representatives of various areas of knowledge. It serves the scientific community of HUUJFJ/EBSERH with the aim of preserving ethical principles in all aspects of the research endeavor. The CEP also helps to protect the researcher, whose study, via CEP. is recognized as one that fulfills the ethical principles defined by Resolution 466/12 of the National Health Council (CNS) [1] and its complementary bodies. Here the objective was to analyze the prevalence of projects approved by the CEP and the principal reasons for delaying approval according to the norms of Res. 466/12, between January 2015 and July 2016. Among the 333 protocols analyzed, $72.9 \%$ were approved, $20.5 \%$ were held for resolution of pending issues, $4.8 \%$ were rejected and $1.8 \%$ were withdrawn. With regard to the reasons for delay in the 68 protocols with pending issues, 32 failed to describe the minimum risks, 17 presented inadequate terms of consent as defined by Res. 466/12, 13 required modification of the chronogram for execution, and 7 did not describe the criteria for inclusion and exclusion of participants. In some cases, more than one issue arose. These data indicate a need for a continuing process of education designed to show professors, researchers and graduate students how to define projects that meet not only bioethical principles but also the expectations for responsible research. We believe that these topics should be taught in responsible conduct of research courses in Brazil's institutions of higher education as a guarantee of respect for the rights and dignity of our human participants.

\section{Reference}

1. BRASIL. Ministry of Health. Resolution $N^{\circ}$ 466, Dec. 12, 2012.

\section{PT.07}

Are perceptions of teachers and students harmonized about plagiarism at school? Results from an ongoing project at a federal school in Brazil

C. C. Santos ${ }^{1,2}$, S. M. R. Vasconcelos ${ }^{1}$

${ }^{1}$ Science Education Program, Institute of Medical Biochemistry Leopoldo de Meis (IBqM), Federal University of Rio de Janeiro (UFRJ), Rio de Janeiro, Brazil; ${ }^{2}$ Department of Biology and Sciences, Pedro II School, Rio de Janeiro, Brazil

Correspondence: C. C. Santos (ccsantos@bioqmed.ufrj.br) Research Integrity and Peer Review 2017, 2(Suppl 1):PT.07

The literature on plagiarism has addressed topics that mostly focus on academic integrity. Some studies look at the frequency of cases, reasons alleged by students, and cultural factors that may explain the practice [1-4]. However, students surveyed allege that the type of assignment can stimulate plagiarism [5]. All over the globe, trying to understand the reasons behind this practice has driven much research, which includes ours [5], but we have investigated plagiarism practices in Brazil considering our school culture. Using a nonprobabilistic purposeful sample, we surveyed 143 science teachers ( $n=42$ valid responses) and 427 ( $n=419$ valid responses) students at one of the most highly regarded federal schools in the country. Our results suggest links between teachers' perceptions of plagiarism and the development of students' creativity. For almost all teachers, plagiarism undermines the creativity of students. Concerning pedagogical 
practices in Brazil, teachers' responses suggest that the way biology, physics and chemistry are taught stimulate more repetition than creativity [6]. Among high-school students, there was a clear lack of consensus. When asked whether the teaching of biology, physics and chemistry at school stimulates more creativity than repetition, about $42 \%$ agree and $47 \%$ disagree. Their views on the extent to which they themselves plagiarize are also diverse. Although we cannot make general claims, our results lead us to consider that plagiarism among students involves subtle pedagogical factors not always considered by educators. It also suggests that the perceptions of these teachers and students about plagiarism are not harmonized in the school environment. This result calls for a broader approach to the questions we address in this ongoing project. Also, as respondents are from one of the most traditional federal schools in Brazil, it is worth investigating whether their views are shared in other similar education centers. This is the next step of the study.

\section{References}

1. McCabe DL. Cheating among college and university students: A North-American perspective. Int J Educ Integ. 2005; 1(1):1-11.

2. Gabriel T. Plagiarism lines blur for students in digital age. The New York Times, 2010 August 1. Available at: http://www.nytimes.com/2010/08/02/ education/02cheat.html? $r=0$.

3. Thomas EE, Sassi K. An ethical dilemma: talking about plagiarism and academic integrity in the digital age. Engl J. 2011; 100(6):47-53.

4. Sureda-Negre J, Comas-Forgas R, Oliver-Trobat MF. Academic plagiarism among secondary and high school students: Differences in gender and procrastination. Comunicar. 2015; 22(44):103-110.

5. Anson CM. Student plagiarism: Are teachers part of the solution or part of the problem? Essays on Teaching Excellence - Toward the Best in the Academy. 2003-04; 15(1). Available from: http://podnetwork.org/content/ uploads/03_04_v15.pdf.

6. Santos CC; Santos PS, Sant'Ana MC, Masuda H, Barboza MB, Vasconcelos SMR.oing Beyond Academic Integrity Might Broaden our Understanding of Plagiarism in Science Education: A Perspective from a Study in Brazil. Ann Braz Acad Sci[online]. 2017. In press. Available at http://www.scielo. br/pdf/aabc/2017nahead/0001-3765-aabc-201720160474.pdf. doi:http://dx.doi.org/10.1590/0001-3765201720160474.

\section{PT.08}

Ethics and integrity in research within the Pontifical Catholic University of Rio Grande do Sul (PUCRS): Research ethics committees and their strategies

D. C. Machado ${ }^{1}$, P. V. S. Souza ${ }^{2}$, R. T. Souza ${ }^{3}$

${ }^{1}$ Research Ethics Committee (CEP), Pontifical Catholic University of Rio Grande do Sul (PUCRS), Porto Alegre, Rio Grande do Sul, Brazil; ${ }^{2}$ Law School, Pontifical Catholic University of Rio Grande do Sul (PUCRS), Porto Alegre, Rio Grande do Sul, Brazil; ${ }^{3}$ Humanities and Ethics Office (EHE), Pontifical Catholic University of Rio Grande do Sul (PUCRS), Porto Alegre, Rio Grande do Sul, Brazil

Correspondence: D. C. Machado (dcm@pucrs.br)

Research Integrity and Peer Review 2017, 2(Suppl 1):PT.08

The process of establishing and improving policies for research, and scientific activities and technological development within the scope of Pontifical Catholic University of Rio Grande do Sul (PUCRS) has ethics as a foundation. Ethical issues are articulated by various institutional bodies, such as Humanities and Ethics Office (EHE), Research Ethics Committee (CEP), the Ethics Committee for the Use of Animals (CEUA), Clinical Bioethics Committee (CBC), Laboratory Practice Monitoring Committee (CAPLAB) and Scientific Committees (CCs) within the different units. They act according to national and international regulations and initiatives, to ensure integrity in scientific research; developing educational activities to foment good scientific practices among researchers (teachers and students); promoting events (conferences, seminars, meetings, lectures, and conferences), training, publications and institutional guidelines, in addition to specific organs that ensure ethics and research integrity. Created on May 17 1990, and currently tied to the Dean of Research, Innovation, and Development (PROPESQ), the CEP-PUCRS is part of the national system called CEP-CONEP, and is a pioneer in the country with regard to Brazilian norms and guidelines that evaluate and approve research projects and protocols involving human subjects. It is an interdisciplinary and independent body, with "munus publico", with advisory, deliberative or educational nature, composed of members representing the various university units. The CEP-PUCRS aims to care for the interest of research participants, their integrity and dignity, contributing to the advancement of knowledge and research within ethically correct standards in the scientific and technological development pursuing quality and excellence in education. Several students, personnel, and professors have attended the training courses offered by the Laboratory Practice Monitoring Committee (CAPLAB) and Research Ethics Committee (CEP) aiming to educate and instruct practitioners of scientific research according to the ethical and integrity doctrines. The CEP is composed of 39 members representing all areas of exact, human, social and biomedical sciences, and up to date, has evaluated around 3,000 research projects and trained all researchers and scientific committees from units where the research involves human beings. The CAPLAB is composed of 15 members, representing all units where there are laboratory activities. CAPLAB has already trained 1,534 individuals on biological safety over a two-year period, as well as 78 on ethics and animal care, 66 on physical risks, and 63 on chemical risks.

\section{References}

Barth WL. Células-tronco e bioética: O progresso biomédico e os desafios éticos. Porto Alegre: EDIPUCRS; 2006. 321 p.

Centers for Disease Control \& National Institutes of Health. Richmond JY, McKinney RW, editors. Biosafety in microbiological and biomedical laboratories. 4th edition. Washington D.C.: U.S. Government Printing Office; 1999. $258 \mathrm{p}$.

Feijó AGS, Braga LMGM, Pitrez PMC. Animais na pesquisa e no ensino: Aspectos éticos e técnicos. Porto Alegre: EDIPUCRS; 2010. 421 p.

Pithan L, Barcellos M. Integridade na pesquisa e propriedade intelectual na universidade. Porto Alegre: EDIPUCRS; 2016. 170 p.

Pontifical Catholic University of Rio Grande do Sul (PUCRS). Plano estratégico 2016-2022. Available at: http://conteudo.pucrs.br/wp-content/uploads/ 2016/01/plano-estrategico-2016-2022.pdf 26 p. Accessed on 2016 Sep 9.

Pró-Reitoria de Pesquisa e Pós-graduação (PUCRS). Guia do mestrando e do doutorando da PUCRS. 2009.

Pró-Reitoria de Pesquisa e Pós-graduação (PUCRS). Ética e integridade na pesquisa. Available at: http://www.pucrs.br/pesquisa/etica-e-integridadeem-pesquisa/\#etica-em-pesquisa. Accessed on 2016 Aug 4.

PT.11

Retractions and scientific production of individual countries: Is there a correlation?

M. D Ribeiro, S. M. R. Vasconcelos

Science Education Program, Institute of Medical Biochemistry Leopoldo

de Meis, Federal University of Rio de Janeiro (IBqM/UFRJ), Rio de Janeiro, Brazil

Correspondence: M. D Ribeiro (mariana.ribeiro@bioqmed.ufrj.br)

Research Integrity and Peer Review 2017, 2(Suppl 1):PT.11

The retraction of scientific articles is usually associated with honest mistakes or practices considered unethical in the scientific community [1]. In the biomedical sciences, "retractions for fraud or suspected fraud as a percentage of total articles have increased nearly 10 -fold since $1975^{\prime \prime}$ [1]. This increase may be attributed to multiple factors, and publication rates are only one among those influencing the rates of retractions in the literature [1-4]. Here, we explored a scientific indicator, the research output of countries, as one possible factor. To explore the relationship between retractions and number of publications, we selected the first 15 countries listed in the Scimago Scientific Journal Rankings (SJR), led by the US and China [5]. We collected retraction notes $(n=676)$ for the whole year 2015, from Retraction Watch [6]. The retractions were classified according to criteria established by the present authors. Retractions for the US $(n=195)$ and China $(n=194)$ made up the greatest fraction together accounting for the largest number of retractions for misconduct (plagiarism; falsification; fabrication): 81 and 124, respectively. We also investigated the prevalence of error and misconduct in the retractions included in our study. The percentage was higher for misconduct, 
$40 \%(n=269)$, followed by error, $6 \%(n=42)$, and unclear reasons, $2 \%$ $(n=15)$. The remaining documents were categorized into "other", which included duplication and authorship disputes. So far, we have not found a correlation between number of retractions and countries' research output. For the US and the UK, for example, it may be that greater engagement in discussions about research integrity and prevalence of journals with better-established editorial policies may be the major factors affecting retraction rates. Here we offer a snapshot of our attempt to look at retractions and their possible association with the research output of countries.

\section{References}

1. Fang F, Grant SCR, Casadevall A. Misconduct accounts for the majority of retracted scientific publications. Proc Natl Acad Sci U S A. 2012: 109(42):17028-17033

2. Cokol M, Ozbay F, Rodriguez-Esteban R. Retraction rates are on the rise. EMBO Rep. 2008 Jan; 9(1):2

3. Corbyn Z. Retractions up tenfold. Times Higher Ed. 2009 Sep 24. Available at: www.timeshighereducation.co.uk/407838.article

4. Steen RG, Casadevall A, Fang FC. Why has the number of scientific retractions increased? PLoS One. 2013 Jul; 8(7)e68397.

5. Scimago Journal \& Country Rank, 2015. Available at: http://www. scimagojr.com/countryrank.php?year=2015.

6. Retraction Watch. Available at: http://retractionwatch.com/.

\section{PT.12}

Perceptions of a group of graduate students in biomedical areas at the Federal University of Rio de Janeiro on research integrity issues

P. Biancovilli, M. Fontes-Domingues, V. C. Garbocci, R. Neves,

M. D. Ribeiro

Science Education Program, Institute of Medical Biochemistry Leopoldo de Meis, Federal University of Rio de Janeiro (IBqM/UFRJ), Rio de Janeiro, Brazil

Correspondence: M. D. Ribeiro (mariana.ribeiro@bioqmed.ufrj.br) Research Integrity and Peer Review 2017, 2(Suppl 1):PT.12

Commitment to honest reporting and reliability of research results is critical to the success of the scientific endeavor. Not only teachers and mentors, but also students are responsible for this success. The responsibility of the researchers goes from the conception of a project to the communication of its results - and the integrity in research in this communication process goes beyond the publication of results. If a researcher produces questionable data, then what kind of knowledge is generated? In the last decades, ethical deviations, problems of reproducibility related to questionable practices in research and misconduct have threatened the reliability of research knowledge [1-4]. In this sense, students and supervisors should be exposed to the theme "research integrity" or, as widely used, "responsible conduct in research" $[5,6]$. The Institute of Medical Biochemistry Leopoldo de Meis, UFRJ, has offered the discipline "Responsible Conduct in Research". The aim is to discuss research integrity, good scientific practices, misconduct and questionable practices in science. The discipline also stimulates debate over these topics in the context of the publication system and of the day-to-day graduate work. After completing the course in 2016, the present authors sought to verify the perceptions of participants: Exploring the central idea "now we know" (post-course feedback), a small survey was designed using the Survey Monkey platform, with five assertions. Of the 45 students who took the course (2015-2016), we got 17 answers. Respondents $(n=17)$ agreed with the idea that "research integrity can strengthen reproducibility in science". Of these respondents, 15 agreed that their day-to-day research attitudes would change from the knowledge they acquired. In this poster, we aim to present the scope of the course through the results of the survey and share our perception of the discipline as students and authors of this work.

\section{References}

1. Marcus A, Oransky I. Science publishing: The paper is not sacred. Nature. 2011 Dec; 480 (7378): 449-450

2. Oransky I. How publish or perish promotes inaccuracy in science-and journalism. AMA J Ethics. 2015 Dec; 17(12):1172-1175.

3. Fanelli D. How many scientists fabricate and falsify research? A systematic review and meta-analysis of survey data. PloS One. 2009 May; 4(5): e5738.

4. Joskow PL. Research integrity and reproducibility. In: Alfred P. Sloan Foundation 2014 Annual Report:New York, NY 2015, p.13-23. Available at: : http://microbe.net/wp-content/uploads/2016/05/2014-AnnualReport-copy.pdf.

5. Science Europe - Research Integrity Practices in Science Europe Member Organisations 2016. Brussels, BE. 52 p. Available at: http//www.scienceeurope. org/uploads/PublicDocumentsAndSpeeches/SCsPublicDocs/Science\%20_ Europe_Integrity_Survey_Report_July_2016_FINAL.pdf

6. Vasconcelos SMR, Sorenson MM, Watanabe EH, Foguel D, Palácios M. Brazilian science and research integrity: Where are we? What next? An Acad Bras Cienc 2015. 87:1259-1269.

\section{PT.13}

Ethical, legal and cultural questions about plagiarism in basic education: An educational project with teachers in a municipality of Rio de Janeiro

R. Amaral', S. M. R. Vasconcelos ${ }^{1,2}$, M. M. M. Machado ${ }^{3}$

${ }^{1}$ Professional Masters Program in Science Education, Institute of Medical Biochemistry Leopoldo de Meis (IBqM), Federal University of Rio de Janeiro (UFRJ), Rio de Janeiro, Brazil; ${ }^{2}$ Science Education Program,

Institute of Medical Biochemistry Leopoldo de Meis, Federal University of Rio de Janeiro (IBqM/UFRJ), Rio de Janeiro, Brazil; ${ }^{3}$ Municipal Bureau of Education, Buzios, Brazil

Correspondence: R. Amaral (rose.amaral03@gmail.com)

Research Integrity and Peer Review 2017, 2(Suppl 1):PT.13

Plagiarism has been receiving growing attention in academia and at school. In basic education, this problem poses a challenge for both educators and students, leading to actions for combating and preventing cases [1, 2]. In the last decades, with the increase of Internet access, students in basic education, in addition to copying/pasting, have sought ghostwriters [3, 4]. In Brazil, although there is still a shortage of research data on the extent of plagiarism at schools, plagiarism practices among students have been increasingly debated. These practices raise ethical and pedagogical issues that need further attention of educators [5, 6]. In Brazil, ethical aspects involved in plagiarism may be addressed through the Political Pedagogical Project of schools, for example. However, there are cultural and legal factors that are not well understood among teachers themselves and other professionals at schools. In this project, we established a partnership with the Municipal Bureau of Education in Búzios to develop educational activities that address different facets of plagiarism in the classroom. Teachers of science, biology, mathematics, physics, chemistry and Portuguese $(n=38)$ participated in workshops focused on plagiarism, exploring cultural and educational aspects (Workshop 1, May 2016) as well as ethical and legal issues (Workshop 2, June 2016). Participants were invited to collaborate in designing a "Booklet on Plagiarism at School". The Booklet, in its initial stage of production, takes an unusual approach to plagiarism: not only the specialists who taught the workshops, but also teachers who attended and even some of the local students are expected to influence the design of the material. We will present an overview of the project and the activities developed in the workshops. This educational material will include, in addition to formal guidelines on plagiarism, a little bit of culture and literature, harmonized with the current environment of public schools in the region.

\section{References}

1. McCabe D, Trevino L. Individual and contextual influences on academic dishonesty: A multi-campus investigation, Res High Educ. 1997; 38(3):379-396. 
2. Carroll J, Zetterling CM. Guiding students away from plagiarism [Internet]. 2009 ISBN 978-91-7415-403-0 [cited 2016 Aug 6]. Available from: https:// www.kth.se/polopoly_fs/1.656375!/Guidingstudents\%20away\%20from\% 20plagarism.pdf.

3. Berret D. An academic ghostwriter, the 'shadow scholar', comes clean. Chronicle of Higher Education [Internet]. 2012 [cited 2016 Aug 6]. Available from: http://chronicle.com/article/An-Academic-GhostwriterComes/133904/.

4. White JL. Shadow scholars and the rise of the dissertation service industry: Can we maintain academic integrity? J Res Pract [Internet]. 2016 [cited 2016 Aug 6]; 12(1). Available from: http://jrp.icaap.org/index.php/ jrp/article/view/536/448

5. Bonette LMC, Vosgerau DSR. O plágio por meio da internet: Uma questão ética presente desde o ensino médio. Educ Revista Marília [Internet]. 2010 jul-dez [cited 2016 Aug 6]; 11(2):7-22. Available from: http://www2.marilia.unesp.br/revistas/index.php/educacaoemrevista/ article/viewFile/2318/1903.

\section{PT.17}

Research integrity, reproducibility and cultural practices in the lab: Insights from an ongoing project in Brazil

P. M. Lourenço, S. M. R. Vasconcelos

Science Education Program, Institute of Medical Biochemistry Leopoldo de Meis (IBqM), Federal University of Rio de Janeiro (UFRJ), Rio de Janeiro, Brazil

Correspondence: P. M. Lourenço (patrick.lourenco@bioqmed.ufrj.br) Research Integrity and Peer Review 2017, 2(Suppl 1):PT.17

Scientific production is an indicator of economic growth that has been gaining prominence in recent decades [1]. With the growth of scientific production, attention has also been paid to the theme "ethics and integrity in science", gaining growing attention from research institutions and research agencies. In Brazil, the Code of Good Scientific Practices of São Paulo Research Foundation (FAPESP) [2] the Directives on Research Integrity of the National Council for Scientific and Technological Development (CNPq) [3], and the Brazilian Meeting on Research Integrity, Science and Publication Ethics (BRISPE) [4] are among the initiatives. Increasingly, research integrity has proved to play an important role in current discussions about reproducibility in science. Current concerns over the irreproducible data and cases of misconduct have posed clear ethical challenges for authors in basic and applied sciences $[5,6]$. In this project, our hypothesis is that the research culture in the labs favors a climate of trust and confidence between students and supervisors rather than a climate focussed on crosschecking the data. This hypothesis will be investigated through a collaborative exploratory study involving Brazilians and two American researchers - one from Virginia Tech and another from St. John's University. This qualitative research in its initial phase seeks to understand how young and experienced scientists (biomedical sciences and engineering) perceive editorial policies implemented in the last decade to foster responsible research and publication ethics. The aim of the study is to help promote the incorporation of good research practices, including good data management, among research groups in Brazil. In this contribution, we will share the initial ideas of the project, exploring the relationship between historical and social aspects in the scientific endeavor and their interaction with the problem investigated.

\section{References}

1. Organisation for Economic Co-operation and Development. OECD Policy Brief: Science, technology and innovation in the new economy. Paris: OECD; 2000, Set. ISBN: 92-64-18297-7, 252 p

2. FAPESP. Código de boas práticas científicas. São Paulo: FAPESP; 2011. São Paulo Research Foundation (FAPESP). FAPESP's Code for Good Research Practices (2011), São Paulo. Available at: http://www.fapesp.br/ boaspraticas/codigo_050911.pdf

3. Conselho Nacional de Desenvolvimento Científico e Tecnológico (CNPq) Diretrizes sobre Integridade da Pesquisa. Available at: http://cnpq.br/diretrizes
4. First Brazilian Meeting on Research Integrity, Science and Publication Ethics. I Brispe; 2010 dez 10-16 [cited 12 jun 2016]; Rio de Janeiro e São Paulo, Brasil. Available at: http://www.ibrispe.coppe.ufrj.br/port.php

5. Mullane K,Williams M. Bias in research: The rule rather than the exception? Discussing some of the causes and prevalence of bias in the fields of biomedical research. 2013. Available at: https://www.elsevier.com/editorsupdate/story/publishing-ethics/bias-in-research-the-rule-rather-than-theexception.

6. Baker M. First results from psychology's largest reproducibility test. Nature 2015.doi: 10.1038/nature.2015.17433. Available at: http://www.nature.com/ doifinder/10.1038/nature.2015.17433.

\section{PT.18}

Young Scientist Prize: An opportunity to discuss scientific integrity in primary and secondary school?

V. Ronchi ${ }^{1,2}$, P. M. Lourenço ${ }^{3}$

${ }^{1}$ Professional Masters Program in Science Education (MP-EGeD), Institute for Medical Biochemistry Leopoldo de Meis (IBqM), Federal University of Rio de Janeiro (UFRJ), Rio de Janeiro, Brazil; ${ }^{2}$ Roberto Marinho Foundation (FRM), Rio de Janeiro, Brazil; ${ }^{3}$ Science Education Program, Institute of Medical Biochemistry Leopoldo de Meis (IBqM), Federal University of Rio de Janeiro (UFRJ), Rio de Janeiro, Brazil

Correspondence: V. Ronchi (vanessaclr@hotmail.com) Research Integrity and Peer Review 2017, 2(Suppl 1):PT.18

Science prizes are important tools in the effort to popularize science [1]. In 1981, the Brazilian National Council for Scientific and Technological Development (CNPq) - pioneer in awarding science prizes in Brazil - created the Young Scientist Prize (PJC) and, in 1982, the Roberto Marinho Foundation (FRM) became a partner in this initiative. The objectives of the PJC are to stimulate research and instil scientific culture in Brazil [2]. Until the end of the 1990's, the prize was awarded to university undergraduates and graduate students. In the 2000's, however, the award was extended to include primary- and secondary-school students [3]. This addition led to new challenges in the area of ethics and scientific integrity. In its selection process, the PJC adopts practices designed to eliminate proposals that violate ethical/moral principles and/or commit plagiarism. Here we cite an unpublished case directly related to ethics in the social realm [4]. A project submitted by an adolescent, with guidance from his teacher, proposed a way of reducing costs in the budgets of the Brazilian prison system. The text revealed a logic in ideas and a "technical-scientific" approach that were unexpected for a child of that age: he suggested adopting a system of combat among prisoners convicted of heinous crimes, along the lines of the public spectacles between gladiators in Ancient Rome. The loser woul be put to death and the winner set free. Over the long term there would be a reduction in costs, and evidently an economic gain for the government. The proposal was eliminated during the preliminary screening by the prize committee. The proposal appears to reveal an important gap with respect to ethics and scientific integrity in the conceptualizing of projects by primary and secondary school students, a requirement already recognized at the II BRISPE meeting [5]. In this poster, the aim is to present the role of the PJC in fostering scientific culture in Brazil, but also to use this case to point out the role of the classroom in creating an interface between this culture and scientific integrity.

\section{References}

1. Moreira IC. A inclusão social e a popularização da ciência e tecnologia no Brasil. Inc Soc. [Internet]. 2006; [cited 2016 Sept 05]; 1:11-16. Available from: http://revista.ibict.br/inclusao/article/view/1512/1707

2. Prêmio Jovem Cientista [Internet]. Brasília: Conselho Nacional de Desenvolvimento Científico e Tecnológico; [2014; cited 2016 Set 05] Available from: http://jovemcientista.cnpq.br/. Portuguese.

3. Conselho Nacional de Desenvolvimento Científico e Tecnológico. Prêmio Jovem Cientista: 30 anos Revelando Talentos e Impulsionando a Pesquisa. 1st ed. Brazil: Brasília; 2011; 14. Portuguese. 
4. Spink MJP. A ética na pesquisa social: Da perspectiva prescritiva à interanimação dialógica. Psico (Porto Alegre). 2000; 31:7-22

5. Second Brazilian Meeting on Research Integrity, Science and Publication Ethics (II Brispe); 2012 May 28 - June 1; Rio de Janeiro, São Paulo, Porto Alegre, Brazil.

\section{Oral presentations}

\section{CO.02}

Implementation of a scientific integrity committee at the Oswaldo Cruz Institute of the Oswaldo Cruz Foundation: Experiences and challenges: looking to the future and the clues to the development of science with social responsibility

M. C. Cassimiro (cassimir@ioc.fiocruz.br)

Scientific Integrity Committee, Oswaldo Cruz Institute, Oswaldo Cruz

Foundation (IOC/FIOCRUZ), Rio de Janeiro, Brazil

Research Integrity and Peer Review 2017, 2(Suppl 1):CO.02

In December 2015, the Scientific Integrity Committee of the Oswaldo Cruz Institute, Cruz Foundation (IOC, FIOCRUZ) was established. The Committee is a multidisciplinary group of researchers from different areas. Their basic knowledge of research integrity (RI) has been gained through the study of the related literature and their participation in national and international events [1, 2, 3, 4]. In 2011 the Brazilian National Council for Scientific and Technological Development (CNPq) created a scientific integrity committee and established $21 \mathrm{di}-$ rectives for RI in Brazil [3]. The Committee at FIOCRUZ has used CNPq guidelines and others, including "Research Integrity: What it Means, Why it is Important and How we Might Protect it" from Science Europe [5], which illustrates the impact that research misconduct brings to scientific development, researchers, institutions and society. According to Fanelli [6], almost $2 \%$ of scientists admitted to having "fabricated, falsified or modified data or results at least once - a serious form of misconduct by any standard - and up to $33.7 \%$ admitted other questionable research practices." In the publication realm, miscondtct explains a large fraction of retractions, which have increased 10-fold whereas the growth in the number of publications has increased only by about $44 \%$, in the last decade [7]. However, questionable research practices have also been a major concern in publications, although they do not necessarily lead to retractions. For example, in recent decades, the dialogue between science and society has reflected concerns about the conflicts of interest and management of such conflicts in publications [8]. Undisclosed conflicts, as widely acknowledged by editors, undermine society's trust in research results [8]. The Committe at FIOCRUZ has discussed these questionable practices, and not only misconduct. The goal is to adopt a comprehensive approach to research integrity at the institution to foster society's trust in research and ethical research with social responsibility.

\section{References}

1. Steneck NH. ORI Introduction to the Responsible Conduct of Research. Washington, DC: US Government Printing Office; 2004.

2. The Brazilian Meeting on Research Integrity, Science and Publication Ethics I, II, III: Available at: http://www.iibrispe.coppe.ufrj.br/index.php/i-brispe. 2010, 2012, 2014

3. $4^{\text {th }}$ World Conference on Research Integrity. Available at: www.wcriz015.org/

4. Roundtable on Research Integrity and Science Communication in the XXI Century. Available at: http://www.fiocruz.br/ioc/media/ 20110912_Programacao_bioetica.pdf 2011.

5. Hiney M. Briefing paper - Research integrity: What it means, why it is important and how we might protect it. [Internet] 2015; Available at: http://www.scienceeurope.org/uploads/PublicDocumentsAndSpeeches/ Briefing_Paper_Research_Integrity_web.pdf.

6. Fanelli $\mathrm{D}$. How many scientists fabricate and falsify research? A systematic review and meta-analysis of survey data. PLoS One 2009; 4(5): e 5738.

7. Noorden R. Science publishing: The trouble with retractions. Nature 2011; 478:26-28.

8. Vasconcelos SMR, Cassimiro MC, Martins MFM et al.. Addressing conflicts of interest in the research paper: A societal demand in contemporary science? Braz J Med Biol Res. 2013; 46:1007-1013.

\section{$\mathrm{CO} .03$}

The open licensing paradigm: The case of Creative Commons for science journals

A. C. Furnival $1^{1,2}$, L. S. Gracioso ${ }^{1,2}$, M. D. P. Silva ${ }^{2}$

${ }^{1}$ Information Science, Federal University of São Carlos (UFSCar), São

Carlos, São Paulo, Brazil; ${ }^{2}$ Graduate Program in Science, Technology and Society, Federal University of São Carlos (UFSCar), São Carlos, São Paulo, Brazil

Correspondence: A. C. Furnival (chloeufscar@gmail.com)

Research Integrity and Peer Review 2017, 2(Suppl 1):CO.03

Information and communication technologies have changed the way in which scientific information is produced, published and communicated. Routine scholarly work means that information is produced predominantly in digital formats, and shared, repurposed and consumed via online media. This modus operandi is today known as digital scholarship. Despite the distribution of electronic documents being easy, simple and cheap, because there are no longer physical, printed entities to be transported, and despite efforts to promote and consolidate open-access and open-science initiatives in research establishments throughout the world, some researchers and end users of scientific publications still experience difficulty in accessing this information, and confusion abounds regarding their freedom to share, reuse or repurpose such information. Yet these ideas of sharing and reusing the results of intellectual activities to create new knowledge are at the core of the "open-science movement", where "open" refers to the granting of copyright permissions beyond those offered by standard copyright law [1]. Inspired by the SPARC pamphlet "HowOpen/slt?" [3], which presents a spectrum of all the possible permutations and degrees of "openness" against which publications can be assessed, we conducted a study on copyright in Latin American journals [2]. We collected data on the copyright policies of 313 journals from the Agricultural, Biological, Health and Engineering sciences, accessible from the Brazilian SciELO platform. As all these journals are considered open access, our aim was to determine the connotation of "open access" adopted by the journal publishers - explicitly or implicitly - as identified in their "copyright policy" and "instructions to authors" sections. The results demonstrated that understandings of the term "open access" vary considerably among the journals examined, painting a confusing picture of each journal's reuse and author rights, and such rights, as laid out in the seminal Budapest Open Access Initiative of 2002, determine the essence of strong open access.

\section{References}

1. Gadamuz A. Open science: Open source licences in scientific research. NCJ Intl L \& Com Reg. 2006; 7(2): 321-366.

2. Furnival ACM, Almeida B, da Silva MD. As políticas de direitos autorais e de reuso presentes nas revistas brasileiras de acesso aberto das áreas biológicas e de saúde disponibilizadas na plataforma SciELO-Brasil. Enc. Bibli: R. Eletr. Bib. Ci. Inf. 2015; 20(44): 25-42.

3. SPARC, PLoS, OASPA. HowOpenlslt? 2013. Available at: https://sparcopen.org/ wp-content/uploads/2016/01/hoii_guide_rev4_web.pdf.

\section{CO.04}

Honor codes: An ex-ante approach to reducing plagiarism

F. M. Litto (frmlitto@terra.com.br)

School of Communications \& Arts, University of São Paulo (USP),

São Paulo, Brazil

Research Integrity and Peer Review 2017, 2(Suppl 1):CO.04

The term "ex-post facto" [from the Latin "after the fact"] refers to the retroactive application of a law or rule of conduct which changes the interpretation or consequences of an action committed beforehand. Its opposite, "ex-ante facto" ["before the fact"], refers to the more just procedure of informing people beforehand what the law, or custom involving an action, requires of them. For example, an educational institution cannot fairly accuse a student or professor of misconduct, such as plagiarism, without proving that the individual concerned 
knew the relevant rules before committing the offense. The same reasoning holds true for entities which publish scholarly articles or books, with relation to potential authors who might or might not understand the rules about academic integrity. Since educational institutions have, as their principal mission, teaching knowledge and certain competencies, as well as the certification of the worthiness of individuals receiving the diplomas they issue, honesty on the part of learners and instructors is of the greatest consequence and seriousness to society in general. Some universities have long used "Honor Codes," or "Academic Honesty Agreements," as a form of fulfilling their obligation to inform and to oblige concordance with explicit, although sometimes somewhat generalized, rules concerning plagiarism. There is evidence that the practice effectly reduces dishonesty. This presentation will offer a range of models, from the simple to the complex, of Honor Codes, that is, of "self-declarations" of cognizance of the rules concerning individual work submitted for evaluation in courses or other learning programs. The wording of such codes, their application, the participation of students in the adjudication of alleged violations of academic dishonesty, the use of online tutorials explaining academic community values, the protection given to informers, the penalties frequently involved, and where to find further detailed information on the subject will be offered.

\section{References}

1. Garvey WD. Communication: The essence of science. Oxford: Pergamon Press; 1979. $332 \mathrm{p}$.

2. Posner RA. The little book of plagiarism. New York: Pantheon; 2009. 128 p.

\section{C0.06}

\section{Scientific integrity: Revisiting the concept}

M. Patrão Neves ${ }^{1,3}$, A. S. Carvalho 1,2, J. Araúijo ${ }^{1,2,4}$, M. C. Cassimiro ${ }^{1,4}$

${ }^{1}$ Bioethics Institute, Catholic University of Portugal, Porto, Portugal;

${ }^{2}$ Office of Ethical Evaluation and Science Integrity, Portuguese

Foundation for Science and Technology, Lisbon, Portugal; ${ }^{3}$ University of the Azores, Ponta Delgada, Portugal; ${ }^{4}$ Scientific Integrity Committee,

Oswaldo Cruz Institute, Oswaldo Cruz Foundation (IOC/FIOCRUZ), Rio de Janeiro, Brazil

Correspondence: J. Araújo (araujojoana@gmail.com)

Research Integrity and Peer Review 2017, 2(Suppl 1):CO.06

We are witnessing an increasing multiplication and complexity of the regulatory codes establishing the correct behavior to comply with scientific integrity, in response to new situations challenging the common concept of integrity. This leads to a proliferation of norms, without coherent articulation or any attempt to categorize and rank the multiple expressions of integrity. In the field of scientific research "integrity" is defined through the identification and characterization of specific situations that constitute actual risks of violating it. From a chronological perspective, identifying improper behaviors often precedes the development of the necessary rules to prevent them; this influences the evolution of the concept, prioritizing the negative what cannot be done - over the positive in the conceptual definition of scientific integrity - what ought to be done -, which constitutes a first characteristic of the conceptual definition of scientific integrity. A second one is the primacy given to the evaluation of the action according to its impact on the research, the researchers and their institutions, over the principles that ground them and the telos or purpose of scientific research, that is, the advancement of knowledge and innovation, in qualitative and quantitative terms. Any action challenging these objectives falls under deontological (professional practice) and also, possibly, moral (character of the actor) scrutiny. Although the definition of "scientific integrity" remains duly open, it is possible to systematize some axial principles in responsible research and innovation that are paramount for scientific integrity: truth, rigor and objectivity; independence, impartiality and neutrality; cooperation and honesty; transparency and fairness; commitment and social responsibility. These allow us to propose an objective and comprehensive definition of "scientific integrity", as well as a coherent framework to firmly establish the procedures required during the research process, and to classify violations to it, contributing to the elaboration of a common standard for global research.

\section{References}

1. Davis MS, Riske-Morris M, Diaz SR. Causal factors implicated in research misconduct: Evidence from ORI case files. Sci Eng Ethics. 2007; 13:395-414.

2. Kaiser, M. The integrity of science-Lost in translation? Best Pract Res Clin Gastroenterol. 2014; 28:339-347.

3. Fanelli, D. How many scientists fabricate and falsify research? A systematic review and meta-analysis of survey data. PLoS One.2009; 4(5)e5738. doi:10.1371/journal.pone.0005738.

4. Office of Research Integrity (US)Annual Report 2012. [Internet]U.S Department of Health and Human Services.[Internet] Available at: https://ori.hhs.gov/ images/ddblock/ori_annual_report_2012.pdf. [Access on: 2016 Jan 27]. email: askORI@hhs.gov.

5. Lu SF, Jin GZ, Uzzi B, Jones B. The retraction penalty: Evidence from the Web of Science. Sci Rep[Internet]. 2013; 3:3146 doi:10.1038/srep03146.

6. Faunce TA, Jefferys S. Whistleblowing and scientific misconduct: Renewing legal and virtue ethics foundations. Med Law. 2017; 26:567-584.

\section{C0.07}

The current dynamics of the correction of the literature adds to the challenges for responsible science communication by science journalists: Insights from an ongoing project

S. Liskauskas' ${ }^{1}$, S. M. R. Vasconcelos ${ }^{1,2}$

${ }^{1}$ Professional Masters Program in Science Education, Institute of Medical

Biochemistry Leopoldo de Meis (IBqM), Federal University of Rio de Janeiro (UFRJ), Rio de Janeiro, Brazil; ${ }^{2}$ Science Education Program,

Institute of Medical Biochemistry Leopoldo de Meis, Federal University of Rio de Janeiro (IBqM/UFRJ), Rio de Janeiro, Brazil

Correspondence: S. Liskauskas (suzana.liskauskas@gmail.com)

Research Integrity and Peer Review 2017, 2(Suppl 1):CO.07

Evidence of lack of integrity in scientific publications has grown rapidly since the 1980s. In the US, integrity and public confidence in scientists have always been the basis for justifying the granting of billions of dollars for research [1]. However, the untainted image of scientists has been challenged. Among the challenges are increasing cases of research misconduct $[1,2]$. The fraud in stem cell research by Hwang Woo-Suk [3] is an example. This case received enormous public attention and showed that prestigious journals are not immune to bogus data. Today, while scientists are expected to boost their publication record - often within a short time - a commitment to research integrity is expected, and it is fundamental for reliable research [4]. Flaws in this process may partially explain the increase in the number of retractions. On the one hand, this increase favors the health of the scientific literature, but on the other, correcting the science imposes changes that include the way it is communicated to the public [5, 6]. Science journalists play a crucial role in informing the public about research results. The way these professionals deal with the correction of the literature is a concern. The single study syndrome [6], in which journalists use a single study to grab the audience's attention, for example, reinforces the concern, and the following questions seem reasonable: (1) What are the media responses to cases of retractions of great repercussion in science? (2) What is the familiarity of scientific journalists with mechanisms for the correction of the scientific literature? (3) What challenges do Brazilian journalists face in informing the public about the current dynamics of science communication? This project addresses these questions, drawing upon evidence from the academic and journalistic literature and upon the views of a sample of science journalists from Rio and São Paulo.

\section{References}

1. Lafollette MC. The evolution of the "scientific misconduct" issue: An historical overview.Proc Soc Exp Biol Med. 2000 Sep; 224(4):211-215.

2. Fanelli D. How many scientists fabricate and falsify research? A systematic review and meta-analysis of survey data. PloS One. 2009 May; 4(5):e5738.

3. Cyranosky D. Woo Suk Hwang convicted, but not of fraud. Nature. 2009 Oct; 461 (7268): 1181.

4. Schwartzman S. Publicar ou morrer. 27 dez. 2013. In: http://www.schwartzman org.br/sitesimon/?p=4777\&lang=pt-br [cited 2016 July 31]

5. Marcus A, Oransky I. Science publishing: The paper is not sacred. Nature 2011 Dec; 480 (7378): 449-450.

6. Oransky I. How publish or perish promotes inaccuracy in science-and journalism. AMA J Ethics. 2015 Dec; 17(12):1172-1175. 


\section{C0.09}

Ethics and research integrity: The role of ethics committes in regulating and protecting scientific research at the Fluminense Federal University

R. Kant de Lima', S. C. Bourguignon', F. R. Mota', H. G. Falcão ${ }^{2}$

${ }^{1}$ Vice-Rectory for Research, Graduate Studies and Innovation (PROPPI),

Fluminense Federal University (UFF), Niteroi, Rio de Janeiro, Brazil;

${ }^{2}$ Graduate Program in Anthropology (PPGA), Fluminense Federal

University (UFF), Niteroi, Rio de Janeiro, Brazil

Correspondence: F. R. Mota (reismota@gmail.com)

Research Integrity and Peer Review 2017, 2(Suppl 1):CO.09

In this report we reflect on the process of creating and consolidating the Research Ethics Committees (CEP's) in Natural Sciences and Humanities at the Fluminense Federal University (UFF). Based on the experience developed in the context of the Vice-Rectory for Research, Graduate Studies and Innovation (PROPPI) - the administrative entity that encompasses the university's Ethics Committees - we will discuss the implications of the epistemiological diversity that underlies the practices and multiple research ethics in the areas mentioned above. In particular, we Will explore the activities undertaken by Ceps in Social Sciences, Applied Social Sciences, Humanities, Letters, Arts and Linguistics (CEP-Humanities), Biosafety (CIBIO), Animal Experimentation (CEUA) and Access to Humam Genetic Heritage and Associated Traditional Knowledge (UFFGEN), with the aim of emphasizing the different ways of dealing with research ethics in different fields. Finally, in view of the emergence of different regulatory models, including the definition of criteria for evaluating and standardizing ways of doing science, we will attempt to analysze crittically the models, logic and practices of these Committees. In this context, we expect to call attention to the need for replacing the "inquisitorial principles" of the political, juridical and moral culture of Brazilian society with a model based on protection of researchers, the institution where they work and the subjects (participants) in the research enterprise.

\section{CO.10}

The detection of plagiarism and self-plagiarism in the articles submitted to the journals of the Federal University of Goiás J. C. Amaral, A. C. Quintela

Centro Editorial e Gráfico, Universidade Federal de Goiás (UFG), Goiânia, Goiás, Brazil

Correspondence: A. C. Quintela (corbachoq@rocketmail.com)

Research Integrity and Peer Review 2017, 2(Suppl 1):CO.10

According to the Brazilian Academy of Sciences, plagiarism and selfplagiarism are bad scientific conducts that hurt the principles of the research practice. Plagiarism and self-plagiarism are realities facing the UFG Journals Division since 2015. These practices can be corrected by recantation, but they tarnish the reputation of the journal and the institution. In our study, we evaluated how the UFG journals with the best classification in terms of intellectual production (QUALIS) deal with the problem of plagiarism and self-plagiarism. In Brazil, the Scientific Electronic Library Online (SCiELO) defines criteria and policies for the development of journals with quality..One of them is that every journal should make available its instructions for submission of manuscripts. In this study we analyzed, in the websites of the older and more reputable UFG journals - Inter-Ação, Pesquisa Agropecuária Tropical and Revista de Patologia Tropical, the guidelines given on plagiarism and self-plagiarism in the section About $>$ Submissions > Guidelines for authors. All journals have guidelines on scope, document publishing, formatting text and illustrations and procedures for submission. It's in the sub-item about conditions for submission where readers find the rules regarding plagiarism and self-plagiarism. Pesquisa Agropecuária Tropical does not accept papers already published in conference proceedings. All three require original manuscript and are not yet listed by Thomson Reuters. Only Inter-Ação states that it uses a plagiarism and self-plagiarism detector. The Revista de Patologia Tropical only mentions plagiarism detection. From the experience of the UFG Journals Division, we show, first, a classification of types of plagiarism and their possible causes. We conclude that the UFG journals do not explicitly confront the question of scientific misconduct and we present a proposal for how to do this in order to avoid retractions.

References

1. Brazilian Academy of Sciences. Rigor e integridade na condução da pesquisa científica: guia de recomendações de práticas responsáveis [Internet]. 2013. [cited 2016 Aug 8]: [11 p]. Available from: http://www. abc.org.br/IMG/pdf/doc-4311.pdf.

2. Inter-Ação, Journal of the Faculty of Education of the Federal University of Goiás, Brazil. Sobre a revista: Diretrizes para autores [Internet]. 2016. [cited 2016 Aug 9] Available from: https://www.revistas.ufg.br/interacao

3. Pesquisa Agropecuária Tropical, Agronomy School of the Federal University of Goiás, Brazil. Sobre a revista: Diretrizes para autores [Internet]. 2016. [cited 2016 Aug 9] Available from: https://www.revistas.ufg.br/pat.

4. Revista de Patologia Tropical, Tropical Pathology and Public Health Institute of the Federal University of Goiás, Brazil. Sobre a revista: Diretrizes para autores [Internet]. 2016. [cited 2016 Aug 9] Available at: https://www.revistas.ufg.br/iptsp.

5. Scientific Electronic Library Online. Critérios, política e procedimentos para a admissão e a permanência de periódicos científicos na Coleção SciELO Brasil [Internet]. 2014. [cited 2016 Aug 8]: [30 p] Available at: http://www.scielo.br/avaliacao/20141003NovosCriterios_SciELO_Brasil.pdf.

\section{Co.11}

The role of research ethics committees in fostering the responsible conduct of research after protocols' approval: A perspective from a Brazilian committee

A. Schtscherbyna', A. Palma', S. M. R. Vasconcelos ${ }^{1,2}$, C. A. Guimarães ${ }^{1}$ Research Ethics Committee, Clementino Fraga Filho University Hospital (HUCFF), Federal University of Rio de Janeiro (UFRJ), Rio de Janeiro, Brazil; ${ }^{2}$ Science Education Program, Institute of Medical Biochemistry Leopoldo de Meis (IBqM), Federal University of Rio de Janeiro (UFRJ), Rio de Janeiro, Brazil

Correspondence: A. Schtscherbyna (anniebyna@yahoo.com.br) Research Integrity and Peer Review 2017, 2(Suppl 1):CO.11

Research Ethics Committees for the Protection of Human Subjects assess the ethics of projects involving human participants, which focus mostly on biomedical and/or behavioral research questions. This assessment is required in many countries, and these Committees analyze research projects at their onset [1-3]. In Brazil, there are over 700 Research Ethics Committees (CEPs) [4]. They have assessed an increasing number of research protocols, partly due to the expansion of the Brazilian science and technology system [5]. The National Commission for Research Ethics (CONEP) oversees the activities of CEPs through federal regulation by the National Health Council (CNS). According to this regulation, CEPs share responsibility with researchers doing CEP-approved human-subject research. However, monitoring the conduct of projects after protocol approval is a difficult task. The CEP/CONEP System relies on the integrity of the research approved and requires that reports be issued every six months by the principal investigator. Yet, it is not uncommon for researchers to skip this step, which renders CEP with fewer possibilities to accomplish their mission of sharing responsibility. In times of increasing accountability, the CEP of Clementino Fraga Filho University Hospital (CEP/HUCFF) at the Federal University of Rio de Janeiro (UFRJ) has developed initiatives - and implemented some - to enhance oversight of projects. In 2015, CEP/HUCFF approved 170 protocols. Pending reports are now required for researchers submitting amendments, for example. Additionally, pending final reports for projects that have been completed will be requested. In this presentation, the goal is to give an overview of the actions that CEP/HUCFF have implemented to better share its ethical/social responsibility with researchers in their conduct of research. We believe these actions can help foster an ethical attitude - particularly among young investigators - and may be an asset for responsible science in research involving humans at the university. 


\section{References}

1. Institutional Review Boards, Ethics Guidance Program, Section 474, Public Law 93-348, in U.S. Congress, Office of Technology Assessment, Biomedical Ethics in U.S. Public Policy —Background Paper, OTA-BP-BBS-105. 1993 (Washington, DC: U.S. Government Printing Office).

2. Council for International Organizations of Medical Sciences (CIOMS). International Ethical Guidelines for Biomedical Research Involving Human Subjects. 2002. Available at: http://www.cioms.ch/publications/guidelines/ guidelines_nov_2002_blurb.htm

3. European Commission. Ethics for Researchers. Facilitating Research Excellence in FP7. Luxembourg: Publications Office of the European Union. 2013. Available at: http://ec.europa.eu/research/participants/data/ ref/fp7/89888/ethics-for-researchers_en.pdf

4. Ministry of Health. National Health Council. National Commission for Research Ethics - CONEP. Plataforma Brasil. [Brazil Platform]. Available at: http://aplicacao.saude.gov.br/plataformabrasil/login.jsf;jsessionid= E42B8A2C14B6CFFA8F332B71COF131AA.server-plataformabrasil-srvjpdf132 Portuguese

5. Silva HP. Science, Technology and Innovation in the Brazilian Unified Health System. 2014. Available at: http://www.hinnovic.org/science-techinnovation-brazil-sus/

\section{C0.12}

An institutional approach to research integrity at a federal university in Brazil: Lessons learned

S. M. R. Vasconcelos, D. Foguel, E. H. Watanabe, R. M. V. R. Almeida, A.

Palma, J. R. Lapa e Silva, M. M. Sorenson

Committee on Research Integrity (CRI), Advisory Council for Research Ethics (CTEP), Federal University of Rio de Janeiro (UFRJ), Rio de Janeiro, Brazil

Correspondence: M. M. Sorenson (sorenson@bioqmed.ufrj.br)

Research Integrity and Peer Review 2017, 2(Suppl 1):C0.12

The US Office of Research Integrity (ORI) was established in 1989 [1]. According to the US ORI, "each Institution that applies for research, research-training, or research related grants or cooperative agreements under the United States Public Health Service (PHS) Act is required to maintain a misconduct in science assurance with this office." [2]. Although different research systems have different ORI or ORI-like models, most of these Offices should help investigate research misconduct and assist institutions/universities with handling allegations. In Latin America, where research integrity is a recent topic in science policy and education, an ORI-like model seems unlikely [3]. However, the call for research integrity oversight is increasing. In Brazil, the major state funding agency, São Paulo Research Foundation (FAPESP), funds about $50 \%$ of Brazilian science [4]. In São Paulo, FAPESP requires that "all research institutions should have an office exclusively responsible for receiving allegations of scientific misconduct related to research carried out at the institution... if needed, initiating and coordinating the investigation of the alleged facts." [5]. In Rio, there is no formal requirement, but some universities have taken initiatives. The Federal University of Rio de Janeiro (UFRJ) is a case in point. A committee on research integrity $(\mathrm{CRI})$, one of the six committees of the Advisory Council for Research Ethics (CTEP) [6], was established in 2014. The main role of $\mathrm{CRI}$ is developing educational measures to foster research integrity and provide advice in allegations of research misconduct or questionable research practices in graduate programs. The committee is also responsible for overseeing research integrity for $\mathrm{NIH}$-funded projects at UFRJ, following US ORI requirements for international research. This presentation will offer an overview of CRI/CTEP's approach to closed cases, raising some of the challenges to address allegations considering Brazilian culture and the institutional framework of UFRJ.

\section{References}

1. Steneck NH. ORI Introduction to the Responsible Conduct of Research. Washington, DC: US Government Printing Office; 2004.

2. Office of Research Integrity. Foreign organization statement. 2014; Available at: http://ori.hhs.gov/foreign-organization-statement

3. Heitman E, Litewka S, Vasconcelos SMR. Education in research integrity and governance of science in the United States, Argentina, and Brazil. In: Bretag T, editor. Handbook of Academic Integrity. Singapore: Springer; 2016. pp. 823-846

4. Cruz CHB, Chaimovich, H. Brazil. In United Nations Educational, Scientific and Cultural Organization. UNESCO science report 2010: The current status of science around the world.2010; Available at: http://unesdoc.unesco.org/ images/0018/001898/189883E.pdf

5. FAPESP. Código de boas práticas científicas. São Paulo: FAPESP; 2011. São Paulo Research Foundation (FAPESP). FAPESP's Code for Good Research Practices (2011), São Paulo. Available at: http://www.fapesp.br/ boaspraticas/codigo_050911.pdf3

6. Advisory Council for Research Ethics (CTEP). 2014; [Webpage] Available at: http://www.ctep.ufrj.br/

\section{C0.13}

Proposal for promotion of a culture of research integrity at the Adolfo Lutz Institute (São Paulo, Brazil, 2016)

B. C. Machado ${ }^{1,2}$, A. P. Vicentini ${ }^{1,2}$, A. A. B. Almodóvar ${ }^{1,2}$, R. M. Catarino ${ }^{1,2}$, H. H. Caiaffa Filho ${ }^{2}$

${ }^{1}$ Research Integrity Study Group, Adolfo Lutz Institute, São Paulo, Brazil;

${ }^{2}$ Adolfo Lutz Institute, São Paulo, Brazil

Correspondence: B. C. Machado (bcmachado@ial.sp.gov.br)

Research Integrity and Peer Review 2017, 2(Suppl 1):CO.13

The Adolfo Lutz Institute (IAL), founded in 1940, is the Central Laboratory of Public Health of the State of São Paulo. Its mission is to participate in the epidemiological, sanitary and environmental surveillance actions to prevent, control and eliminate diseases. The IAL does high-complexity tests for surveillance, scientific research and technological innovation and provides training for specialized human resources. It has 1246 employees, approximately $50 \%$ of whom are directly involved in research activities. The IAL is also involved in education/teaching activities and offers scholarships for professional development and for the conduct of research projects in the graduate programs of the State Department of Health. The Institute also publishes a magazine and a bulletin in addition to books and manuals. It has 184 ongoing research projects registered and 57 projects with external support (July, 2016). Society's support for science depends directly on the good conduct of researchers and those responsible for monitoring research activity [1]. In this context, there is an urgent need for the IAL to extend its commitment to promote, ensure and maintain a culture of scientific integrity harmonized with national and international current discussions [2, 3]. Meeting this demand, the general directorate proposed the establishment of an IAL Research Integrity Committee. Initially, a study group was created to work on the implementation. The main pillars of the action plan are educational activities focusing on good practices and preventive activities to avoid research misconduct. Among the committee's duties are the design of integrity policies and the establishment of an advisory body for the IAL scientific community. The IAL committee will contribute to promote ethics and integrity in research conducted at the individual and institutional levels. The committee will also stimulate that responsible and reliable scientific research be fostered among the $I A L$ community for the benefit of society. 


\section{References}

1. Academia Brasileira de Ciências. 2013. Rigor e Integridade na Condução da Pesquisa Científica, 13 p. Available at: http://www.abc.org.br/IMG/pdf/ doc-4559.pdf

2. II Encontro Brasileiro sobre Integridade na Pesquisa, Ética na Ciência e em Publicações - BRISPE. 2012. Declaração Conjunta sobre Integridade em Pesquisa. Available at: http://dx.doi.org/10.1590/S0011-52582012000200009

3. Segunda Conferência Mundial de Integridade na Pesquisa. 2010. Declaração de Singapura, Available at: www.singaporestatement.org

\section{C0.14}

Editors of SciELO Brazil: What is their familiarity with misconduct practices in science?

E. Damasio ${ }^{1,2}$, J. Leta ${ }^{2,3}$

${ }^{1}$ Department of Mathematics Library, State University of Maringá (UEM) Maringá, Brazil; ${ }^{2}$ Information Sciences Program, Federal University of Rio de Janeiro (UFRJ), Rio de Janeiro, Brazil; ${ }^{3}$ Science Education Program, Institute of Medical Biochemistry Leopoldo de Meis, Federal University of Rio de Janeiro (IBqM/UFRJ), Rio de Janeiro, Brazil

Correspondence: E. Damasio (edilsondamasio@gmail.com)

Research Integrity and Peer Review 2017, 2(Suppl 1):C0.14

SciELO is an open access (OA) science journal platform started in Brazil in 2002. Currently, it indexes nearly 300 journals edited in Brazil, called SciELo Brazil [1], and a thousand from other countries. Considering the central role of editors in the publishing process and the increasing number of cases of misconduct in science [2], we designed a survey of all SciELO editors' views on selected research integrity practices. The present abstract focuses on the results obtained from 78-86 respondents and focuses on their familiarity with 11 practices of misconduct in science. We used the Likert-scale ranging from 0 (not familiar) to 3 (highly familiar). "Simultaneous submission" was identified as the highest-scoring practice editors are familiar with, while "manipulation of images" was the lowest, with average values of 2.13 and 1.29 , respectively. Five practices had score means ranging from 1.99 to 1.54: "plagiarism", "conflicts of interest", "redundant publication", "reviewer's misconduct" and "omitted authorship". Another four practices had score means lower than 1.5: "contested authorship", "data fabrication", "data falsification" and "undisclosed commercial ties". This set of results suggests that SciELO editors have a very low level of familiarity with many research misconduct behaviors. A recent study carried out with Wiley-Blackwell journal editors garnered even lower score means ${ }^{3}$. Such a picture suggests that the reliability of the journal editorial flow may be at risk because of a lack of editors' familiarity with the most relevant practices of misconduct in science. This contribution is part of an ongoing study on research integrity knowledge among editors in a major Latin American scientific platform and its possible impact on the editorial policies of its journals.

\section{References}

1. SciELO Brazil. Scientific Electronic Library Online. [Internet]. 2016 Jul 4. Available at: http://www.scielo.br

2. Lafollette MC. Stealing into print: Fraud, plagiarism, and misconduct in scientific publishing. Los Angeles: University of California Press; 1996.

3. Wager E, Fiack S, Graf C, Robinson A, Rowlands I. Science journal editors' views on publication ethics: results of an international survey. J Med Ethics. 2009; 35:348-353.

\section{CO.16}

History of ethical norms adopted from 1962 to 2010 at the Editorial and Graphics Center of the Federal University of Goiás A. C. Quintela (corbachoq@rocketmail.com) Centro Editorial e Gráfico, Universidade Federal de Goiás (UFG), Goiânia, Goiás, Brazil

Research Integrity and Peer Review 2017, 2(Suppl 1):CO.16
We present the results of reviewing and evaluating the editorial norms and the books produced under these norms by the publishing office of the Federal University of Goiás (UFG) [3] between 1962 and 2010. The main aim is to recapture the viewpoints expressed by the agents ("merchants of culture" [6]) who sanctioned the norms that gave rise to these books. In archeological terms, our research was based on the notions of field, symbolic power, and belief [1, 2] in the work of Michel Foucault [5]. Declarations of opposing ethical viewpoints were compared based on the documents recovered from the Editorial and Graphics Center at UFG. We extracted and analyzed the motivations and justifications that, from an ethics perspective, led to three distinct phases in policy and editorial practices over a period of nearly five decades. In the first phase, from the founding of the Center (17.12.1962) to the military coup in 1964, the predominant publications were essays and plans from authors outside the academy, proposing reform and modernization of social fields, as well as literary works and literary criticism. Little was published from academic authors. After the coup, when there was a pronounced increase in academic and scientific studies, works that were published were clearly related to the guidelines/policy directives of successive military and civilian governments. With the new Constitution (1988), the editorial output explaining the policies of the military/civilian regime was cancelled and the Center devoted itself entirely to publishing academic works originating within UFG. Examination of the points of view expressed during these three phases of the Center's existence reveals editorial policies detached from ethical concerns and editorial autonomy. In addition, this scrutiny suggests, based on Cortina [4], indifference to the interests/profile of Brazilian readers and to Society at large.

\section{References}

1. Bourdieu P. A produção da crença: Contribuição para uma economia dos bens simbólicos. 3rd edition. Translated by Guilherme J. de Freitas and Maria da Graça Jacintho Setton. Porto Alegre: Zouk, 2008. 224 p.

2. Bourdieu P. O poder simbólico. 15th edition. Translated by Fernando Tomaz. Rio de Janeiro: Bertrand Brasil; 2011. 318 p.

3. Centro Editorial e Gráfico da Universidade Federal de Goiás. Retrieved from: http://www.cegraf.ufg.br. Accessed on: Jul. 29, 2016.

4. Cortina A. Perfil do leitor brasileiro contemporâneo: Os livros mais vendidos no Brasil de 1966 a 2010. Campinas, SP: Mercado de Letras; 2014. 388 p.

5. Foucault M. A arqueologia do saber. 8th edition. Translated byLuiz Felipe Baeta Neves. Rio de Janeiro: Forense Universitária; 2012. 264 p.

6. Thompson JB. Mercadores de cultura. São Paulo: Editora Unesp; 2013. 488 p.

\section{C0.17}

Digital curation: Research data sustainable use in the Brazilian scenario

L. V. R. Rezende ${ }^{1}$, S. Cruz-Riascos ${ }^{2}$

${ }^{1}$ Faculty for Information and Communication, Federal University of Goiás, Goiânia, Goiás, Brazil; ²Department of Information Science, Federal University of Pernambuco, Recife, Pernambuco, Brazil

Correspondence: L. V. R. Rezende (lauravil.rr@gmail.com)

Research Integrity and Peer Review 2017, 2(Suppl 1):C0.17

This study addresses the concept of digital curation in the context of research data within the Brazilian scientific communication, highlighting the importance of the use, preservation and custody of digital documents in open access. As a guideline, this study presents the concept of digital curation "which involves maintaining, preserving and adding value to digital research data throughout its lifecycle. The active management of research data reduces threats to their long-term research value and mitigates the digital obsolescence risks" [1]. Our project focuses on the Brazilian scene of registration, dissemination and availability mechanisms for access to the scientific literature, emphasizing the issue of digital research data management, especially in projects 
financed by public funds. The vast amount of data produced at research institutes and laboratories should be available to be managed for the best possible use of future generations of scientists. Based on the context, the objective was to carry out an initial mapping of available information on scientific research funded by the Brazilian State Foundations for Research - in particular, to verify research data availability on these foundations' websites, as these investigations are financed with public funds. This study describes a quantitative approach for data collection on the websites of the State Foundations for Research Support in Brazil. The results lead us to draw attention to the need for improvement of the digital data processing and the requirements related to the provision of scientific information, not only in scrapbook format (scientific articles, theses, dissertations), but also the raw data generated during investigations. This initiative aims to promote the democratization of subsidies related to access, use and reuse of information that can contribute to the advancement of future responsible sustainable investigations for research at Brazilian universities.

\section{Reference}

1. Digital Curation Centre. [Internet]. [Edinburgh]. University of Edinburgh; c2004-2016 [cited 2016 Aug 30]. Available at: http://www.dcc.ac.uk/ resources/curation-lifecycle-model.

\section{Co.18}

Relations between integrity and transparency in scientific research

A. Abreu, (anaabreu@ufscar.br)

${ }^{1}$ Teaching Methodology Department, Federal University of Sao Carlos

(UFSCar), Sao Carlos, Sao Paulo, Brazil; ' Urban Studies Laboratory,

Campinas University (UNICAMP), Campinas, Sao Paulo, Brazil

Research Integrity and Peer Review 2017, 2(Suppl 1):CO.18

The production of science is a collective process, in which ethics and integrity are essential, for its effects, among others, on the credibility assigned to the achieved results. Research integrity refers, in short, to values such as intellectual honesty and responsibility, with regard to the formulation and conduction of the research, as well as regarding its disclosure. We comprehend that meanings of words are not static; meanings may shift due to the different conditions of knowledge production, constituted by social, political and economic aspects. We present a part of the project "Achieving research integrity by authorship policies" (FAPESP 2016/04280-6), in which we aim to comprehend the conceptions that circulate nowadays of research integrity, authorship in the scientific field and research misconduct. Our theoretical/methodological perspective is based on a discursive foundation [1-5]. One of the actions we insert in the scope of research integrity policies refers to disclosure - performed by national and international agencies - of cases of scientific misconduct. We examine this process of disclosure in order to understand the relationship between transparency and demands for integrity in research, bringing out some discursive clashes between public and private, productivity and process and their effects on construction of knowledge.

\section{References}

1. Pêcheux M. Semântica e Discurso. Trad. E. Orlandi et al. Campinas, SP: Ed. Unicamp; 1975. p.244

2. Pêcheux M. Ler o arquivo hoje. In: Orlandi E, editor. Gestos de leitura. Campinas, SP: Ed. Unicamp; 1981. p.125

3. Pêcheux M. Discurso: Estrutura ou acontecimento? Trad. E. Orlandi. Campinas, SP: Pontes; 1983. p.62

4. Orlandi E. As formas do silêncio: No movimento dos sentidos. 4th edition. Campinas, SP: Ed. Unicamp; 1997. p.102

5. Orlandi E. Cidade dos Sentidos. Campinas, SP: Pontes; 2004. p.92

\section{CO.19}

The role of policy and the media in promoting research integrity M. Russo (marisaleco@gmail.com)

School of Philosophy, Letters and Humanities, Federal University of São Paulo (UNIFESP), Guarulhos, SP, Brazil

Research Integrity and Peer Review 2017, 2(Suppl 1):CO.19
In recent years, we have seen a major discussion around issues of integrity in research, focusing mostly on scientific misconduct, such as falsification of results by researchers. There has also often been a debate about the role of editors in publications, and sanctions to authors who had articles retracted. However, little has been debated about research conducted responsibly by researchers, but whose results are manipulated or misrepresented by political/economic influences, or are distorted by the media. These problems may have a strong social impact, as they are potential threats to both the credibility and integrity of science as well as to the academic freedom of researchers. This contribution addresses particular cases in which misguided interference of the political/economic spheres and the media led to devastating consequences for the public. Among these cases are the misrepresentation of scientific data on climate change in the US in 2003, which minimized human interference in environmental impacts [1-3]. Another example is the adulteration of data in REACH (European directive for risk from chemical substances) minimizing the actual amount of animals to be used in toxicity research [4]. The pressure thus on scientists and the strong conflict of interests/ lobbyng of companies within the FDA (US) and its relation to distorted published data [5-7] are also addressed. The goal of this work is to draw attention to the need for a science policy that can potentially stregthen the protection of scientific and academic freedom to maintain the integrity of scientific data [8] and access of the public to genuine knowledge produced by researchers.

\section{References}

1. Rest $\mathrm{KM}$, Halpern $\mathrm{MH}$. Politics and the erosion of federal scientific capacity: Restoring scientific integrity to public health science- Am J Public Health. 2007 Nov; 97(11):1939-1944.

2. Clapp R, Hoppin P, Kriebel D. Erosion of the integrity of public health science in the USA.Occup Environ Med. 2006 Jun; 63(6):367-368.

3. Hamburger T. White House tries to rein in scientists. Los Angeles Times. June 26, 2004. Accessed 2016 Aug 18. Available at: http://articles.latimes.com/ 2004/jun/26/nation/na-science26.

4. Cahill A. Mistrust towards policy-makers, not misplaced lobbying. Accessed 2016 Aug 20. Available at: http://www.euroscientist.com/ mistrust-towards-policy-makers-not-misplaced/

5. Fromer MJ. Survey of FDA scientists shows they feel pressure to exclude or alter findings, Oncology Times: 25 August 2006 28(16):12-13,16. Available at: http://journals.Iww.com/oncology-times/Fulltext/2006/ 08250/Survey_of_FDA_Scientists_Shows_They_Feel_Pressure.8.aspx.

6. Kolata G. Scientist who cited drug's risk is barred from FDA panel. New York Times November 13, 2004. Accessed 2016 Aug 18. Available at: http://www.nytimes.com/2004/11/13/politics/scientist-who-cited-drugsrisks-is-barred-from-fda-panel.html.

7. Union of Concerned Scientists. Voices of scientists at the FDA: Measuring progress on scientific integrity. 2012. Accessed 2016 Aug 8, Available at: http://www.ucsusa.org/sites/default/files/legacy/assets/documents/ scientific_integrity/fda-survey-report-2011.pdf.

8. Union of Concerned Scientists. Voices of scientists at FDA: Protecting public health depends on independent science. 2006. Accessed 2016 Aug 8. Available at: http://www.ucsusa.org/sites/default/files/legacy/ assets/documents/scientific_integrity/fda-survey-brochure.pdf.

\section{C0.20}

Construction and validation of an instrument for measuring the moral sensitivity of professionals involved in research on humans

P. G. Camacho ${ }^{1}$, M. Palácios ${ }^{2}$

${ }^{1}$ Clinical Oncology, Federal Hospital for Employees of Rio de Janeiro State (HSE), Rio de Janeiro, Brazil; ${ }^{2}$ Institute for Studies in Public Health (IESC), Federal University of Rio de Janeiro (UFRJ), Rio de Janeiro, Brazil Correspondence: P. G. Camacho (pgcamacho@globo.com)

Research Integrity and Peer Review 2017, 2(Suppl 1):CO.20

Moral sensibility can be defined as the ability to interpret a given situation in terms of what ethical issues are concerned, the possible courses of action, their consequences, and the parties involved. The beginning of the investigation of moral sensibility refers to the work of the moral sentimentalists with the introduction of the moral sense as 
the faculty of distinguishing between right and wrong - ability to experience feelings of approval or disapproval in the face of a fact under evaluation. In a new cognitive perspective, James Rest [1], following the studies of Piaget and Kohlberg [2], proposed the Model of the Four Components determinants for moral behavior, where moral sensitivity is the first. After Rest's initial study of moral sensitivity with dentistry students, many others were developed on the international scene in the various professions. But few studies have focused on professionals involved in scientific research. Investigative models vary between semistructured interviews and open and closed questionnaires. Thus, this research aimed to construct and validate an instrument for measuring moral sensitivity among professionals involved in human-subject research. The instrument is composed of a scenario case, an open questionnaire and a personal data form. For the case-scenario validation, this instrument was submitted to different groups (teachers, graduate students, research ethics committee - CEP) members and bioethics specialists), each in an independent stage, with specific objectives. The case scenario in the context of clinical research was explored using content analysis. Four ethical questions were chosen for proposing a context for the conduct of human-subject research: conflicts of interest, responsibilities among research team members, data management, and respect for participants. In the first stage, with university professors, the case underwent minor changes to comply with the basic criteria proposed. For the panel of experts (bioethicists), we recorded their ability to identify the four ethical issues in the scenario presented. Finally, with CEP members and graduate students, we considered the suitability of the instrument for identifying levels of moral sensitivity. Thus, we discuss the validity of the proposed instrument for the measurement of moral sensitivity in human-subject research, which may be explored for topics in the responsible conduct of research.

\section{References}

1. Rest JR. Moral development: Advances in research and theory. New York: Praeger; 1986. 224 p.

2. Kohlberg L. The Philosophy of Moral Development: Moral Stages and the Idea of Justice. New York: Harper \& Row;1981. 441 p.

\section{C0.21}

Scientific integrity and scientific misconduct: Behavior and conduct among undergraduate students in the health sciences

N. R. A. Silva', M. R. C. G. Novaes' ${ }^{1}$, D. Guilhem ${ }^{1,2}$

${ }^{1}$ Graduate Program in Health Sciences, College of Health Sciences, University of Brasilia (UnB), Brasilia, Federal District, Brazil; ${ }^{2}$ Graduate Program in Nursing, College of Health Sciences, University of Brasilia (UnB), Brasilia, Federal District, Brazil

Correspondence: D. Guilhem (guilhem@unb.br)

Research Integrity and Peer Review 2017, 2(Suppl 1):CO.21

Scientific integrity is an essential requirement for scientific practice. Universities and research institutions, as trainers of future scientists, share responsibility for dissemination of contents focused on building core values and moral responsibilities. The main aim was to understand how undergraduate students from health and biological sciences perceive and practice scientific integrity principles. Observational, cross-sectional study with a quantitative approach. Data collection by interviewing undergraduate research students, preserving anonymity by ballot technique. The questionnaire contained 13 questions in four sections: 1) general data, 2) issues for classifying the level of agreement or disagreement with statements about the research process, 3) self-report of behavior as researcher, 4) ethics training and scientific integrity. One hundred nineteen young scientists participated in the study. Although students had notions of good scientific practice, this issue needs to be constantly revisited. Faced with a hypothetical case of scientific misconduct, $41 \%$ of respondents were neutral about the extent of misconduct and $21 \%$ said they would not report the deviation. Even when ethical guidelines were known, the subjects were not always positioned in the most responsible way. In the items on self-reported behavior, $20 \%$ said they had already started collecting survey data prior to approval by the ethics committee. Researchers' experiences emerge as an important educational space and professional training for students. Good practices in research need to be included earlier in the curriculum, throughout the guidance and training phases.

References

Corbyn Z. Misconduct is the main cause of life-sciences retractions. Nature. 2012:490:21

Pádua GCC, Guilhem D. Integridade científica e pesquisa em saúde no Brasil: Revisão da literatura. Rev. Bioét. 2015;23:124-138.

Russo M. Ética e integridade na ciência: Da responsabilidade do cientista à responsabilidade coletiva. Estud Av. 2014; 28:189-198.menezes

Wright PM. Ensuring research integrity: An editor's perspective. J Manag. 2016; 42:1037-1043. doi:10.1177/0149206316643931

Zunic L, Masic I. What pharmacy practitioners need to know about ethics in scientific publishing. J Res Pharm Pract. 2014; 3:112-116.

\section{CO.22}

Integrity and education - fostering the culture of good practices in research

H. S Selistre-de-Araujo ${ }^{1}$, A. S. C. Abreu²

${ }^{1}$ Departamento de Ciências Fisiológicas, Universidade Federal de São

Carlos (UFSCar), São Carlos, Brazil; ${ }^{2}$ Departamento de Metodologia de

Ensino, Universidade Federal de São Carlos (UFSCar), São Carlos, Brazil

Correspondence: A. S. C. Abreu (anaabreu@ufscar.br)

Research Integrity and Peer Review 2017, 2(Suppl 1):CO.22

The process of strengthening a culture of integrity in research appears as a current challenge to the academic field. In this direction, we highlight the relevance of creating some study groups on the ethics and integrity theme, as well as the important performance of these groups on educational and preventive activities in the field of good scientific practice at the University. We present the process of creation of the Committee on Integrity and Ethics in Research of Federal University of Sao Carlos - UFSCar, with its challenges, in particular, the one of creating effective debate spaces with the community inside and outside the University. Faculty members, graduated and undergraduate students and members of the technical staff form the Committee, about 2-3 persons per category. They expressed an interest in participating voluntarily of the Committee activities, which include monthly meetings, community counselling, and the development of educational material. As a first achieved goal, the UFSCar Research Council approved in 2016, the "Guidelines of Research Integrity at UFSCar", which is available for the community at http://www.propq. ufscar.br/integridade-etica-na-pesquisa. These guidelines are expected to work as a standard rule for researchers at UFSCar for preventing research misconduct such as plagiarism or data manipulation.

Support: Provost for Research, UFSCar, 2015-2016; FAPESP grant 2016/04280-6

\section{Publisher's Note}

Springer Nature remains neutral with regard to jurisdictional claims in published maps and institutional affiliations. 